\title{
GLOBAL MONITORING OF CORAL REEFS
}

\author{
Helen T. Yap \\ The Marine Science Institute, University of the Philippines, Diliman, 1101 Quezon City, Philippines, \\ helentyap@yahoo.com
}

\begin{abstract}
Coral reefs are major shallow-water ecosystems lining the coastlines of the tropical and subtropical belt. They have served the needs of human societies over the millennia, but are now experiencing unprecedented rates of degradation due to combined effects of anthropogenic impact and global climate change. An evolving global monitoring system draws on fundamentals of ecosystem structure and function, and on the continued advances in science and technology. Nevertheless, significant knowledge gaps remain, pertaining particularly to uncertainties in biological responses in the face of new, complex environmental challenges such as increasing temperature and ocean acidification, and how these are manifested in the broader ecosystem dynamics. In implementing a global programme, a major objective should be to engage the extensive network of developing country scientists, where the greatest concentrations of coral reef resources and the highest levels of species diversity are found. Success hinges on commitments by national governments, and on availability of sustained funding.
\end{abstract}

\section{INTRODUCTION}

Coral reefs are among the most significant shallowwater marine habitats lining many coastlines of the tropical and subtropical belt [1]. They are geological structures constructed over millions of years through calcification of the main framework-builders. Over the last few million years, this role has been performed by members of the Order Scleractinia (Phylum Cnidaria), otherwise known as the "hard" or stony corals. Many species of hard corals are in symbiosis with a dinoflagellate (also known as a "zooxanthella") which is able to photosynthesize inside the coral endodermal cell, and is, thus, responsible for a large degree of primary production on a typical coral reef. Of all known ecosystems on earth, coral reefs are among those that harbor the highest levels of biodiversity.

The high species diversity on coral reefs is attributed mainly to their remarkable structural complexity which offers a variety of habitats to shallow-water organisms, and to their location in the tropics and subtropics with their relatively stable light and temperature regimes. The complex water currents that operate on different scales (from microturbulence around individual coral colonies to transport over hundreds of kilometers) are believed to play a role in biological connectivity among habitats. Water masses potentially carry untold numbers of gametes, larvae of invertebrates and fish, algal spores, and plant seeds from one location to several others downstream, thus serving as agents for the dispersal and recruitment of different species. Efforts to protect and manage specific marine populations have gradually incorporated this additional dimension of physical connectivity, via hydrodynamics, among critical habitats [2]. The success of recruitment into an area depends on survival of propagules and larvae during their transport and upon arrival and hinges, in turn, on factors such as degree of water turbulence, predation, adequate food supply (in the case of feeding larvae) and the possible impacts of pollutants in the water column.

Over the millennia, coral reef habitats have provided livelihood to human populations, mainly through harvests of finfish, seaweed and invertebrates. Other important uses of coral reefs include coastal protection from destructive forces of the sea and, more recently, recreation as exemplified by tourism. Recent decades have borne witness to the unprecedented degradation of these important resources, mostly due to or related to human activity [3], cited in [4].

The main anthropogenic causes of reef destruction continue to be overexploitation of living resources, sedimentation from terrestrial sources, pollution (mostly land-based but also increasing from ships, such as oil pollution), and habitat modification associated with coastal development [3], cited in [4]. The overexploitation of reef resources stems largely from heavy subsistence fishing by human populations on the coast. This problem is particularly severe in developing countries. Land-based activities such as agriculture, mining, and construction cause the release of significant quantities of sediment into coastal waters. This issue is closely associated with that of habitat modification. Huge areas of coastal habitat such as mangrove forests, swamps, dunes and beaches have been converted over the decades for direct human use such as settlements, industrial development, urbanization and maritime transport. This has resulted not only in the actual physical disappearance of all kinds of natural ecosystems, but has also caused direct impact on downstream ecosystems such as coral reefs, primarily via the release of sediment and various pollutants. 
The aforementioned causes of reef destruction, particularly those involving physical alterations of the limestone matrix, tend to erode its three-dimensional structure. The diminished structural complexity of damaged reef areas directly undermines the habitats of thousands of species typically inhabiting coral reefs. In addition to the loss of physical shelter and nursery areas, critical energy and biogeochemical pathways are disrupted, threatening the survival of these organisms.

The overexploitation of resources, which, unfortunately, includes the use of destructive fishing techniques such as explosives, results directly in decreased abundances of organisms over time, and even the localized extinction of species. Thus, in combination, the human impacts on coral reef ecosystems have resulted not only in the destruction of the habitat itself, but also in a loss of biodiversity.

Pollution in coral reefs originates from a number of sources. In the developing world, the main threat is likely organic pollution in the form of domestic sewage emanating from dense human populations living along the coasts. The various wastes eventually degrade to yield inorganic nutrients, primarily nitrogen and phosphorus, which promote phytoplankton blooms and/or the proliferation of macroalgae. The release of industrial effluents into coastal waters would present a threat if coral ecosystems are situated in the vicinity. Impacts related to human activities such as tourism would be significant in highly frequented areas. The destruction from tourists is mainly physical, such as due to trampling on the reef, or breakage of corals due to boat anchoring.

More recent concerns regarding the health of coral reef ecosystems derive from the broader sphere of global climate change. The particular issues of interest in this regard are increasing ocean temperatures, rising sea level, increasing ocean acidification, and changes in the pattern, intensity and frequency of tropical storms [4]. These factors only tend to exacerbate the already degraded condition of many reef habitats around the globe. A selected subset of these is dealt with in some detail in this paper. But by way of introduction, an example is the issue of ocean acidification [5]. Increasing levels of carbon dioxide in the atmosphere are largely attributed to human burning of fossil fuels, which is traced back to the beginning of the industrial revolution. One largely accepted prediction is that carbon dioxide concentrations in the ocean will increase correspondingly due to absorption from the atmosphere, lowering $\mathrm{pH}$. This, in turn will decrease aragonite saturation throughout the world's oceans (Fig. 1), seriously impairing calcification mechanisms of a number of marine species. In addition, low aragonite saturation is believed to impede cementation of the reef matrix, rendering it susceptible to erosion [6].

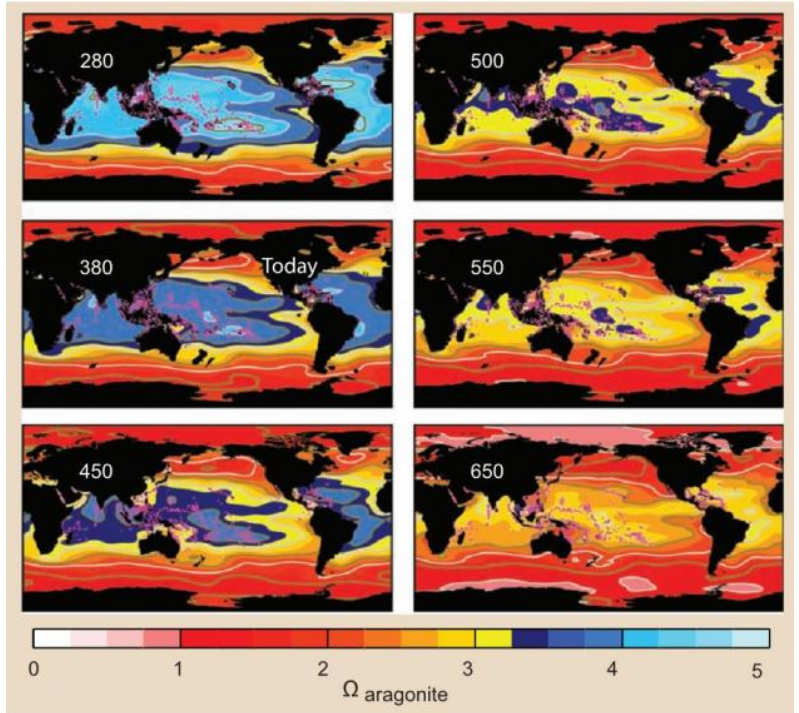

Figure 1. Changes in aragonite saturation predicted to occur as atmospheric carbon dioxide concentrations

(ppm, number at top left of each panel) increase from a value of 280 to a high predicted level of 650 (reproduced, with permission, from [7])

\section{DESIGNING AN OBSERVING SYSTEM BASED ON FUNDAMENTALS OF ECOSYSTEM STRUCTURE AND FUNCTION}

Ecosystems are exceedingly complex, harboring thousands of species. It is impossible to monitor the responses of all species to environmental forcing on an individual basis. Fortunately, ecosystem science has demonstrated that the analysis of complex natural habitats is tractable along two basic lines, namely, structure and function. In the case of coral reefs, the bewildering array of species responses may be distilled into those of key functional groups that are responsible for the main ecosystem functions of primary production and calcification, such as various types of algae, and the hard corals (Fig. 2). Likewise, the plethora of physiological responses and ecological processes on a reef can be collapsed into those that ultimately help maintain overall ecosystem function, such as grazing (which keeps natural populations in check) and recruitment (responsible for the replenishment of individuals in a community). Environmental stresses such as warming and acidification that are associated with global climate change are seen to act on key functional groups and processes (which may be regarded as nodes in the system) which will in turn result in broad system effects because of positive and negative feedback.

Various aspects of reef ecosystem structure and function are amenable to measurement by different techniques that can be part of a global observing system. 


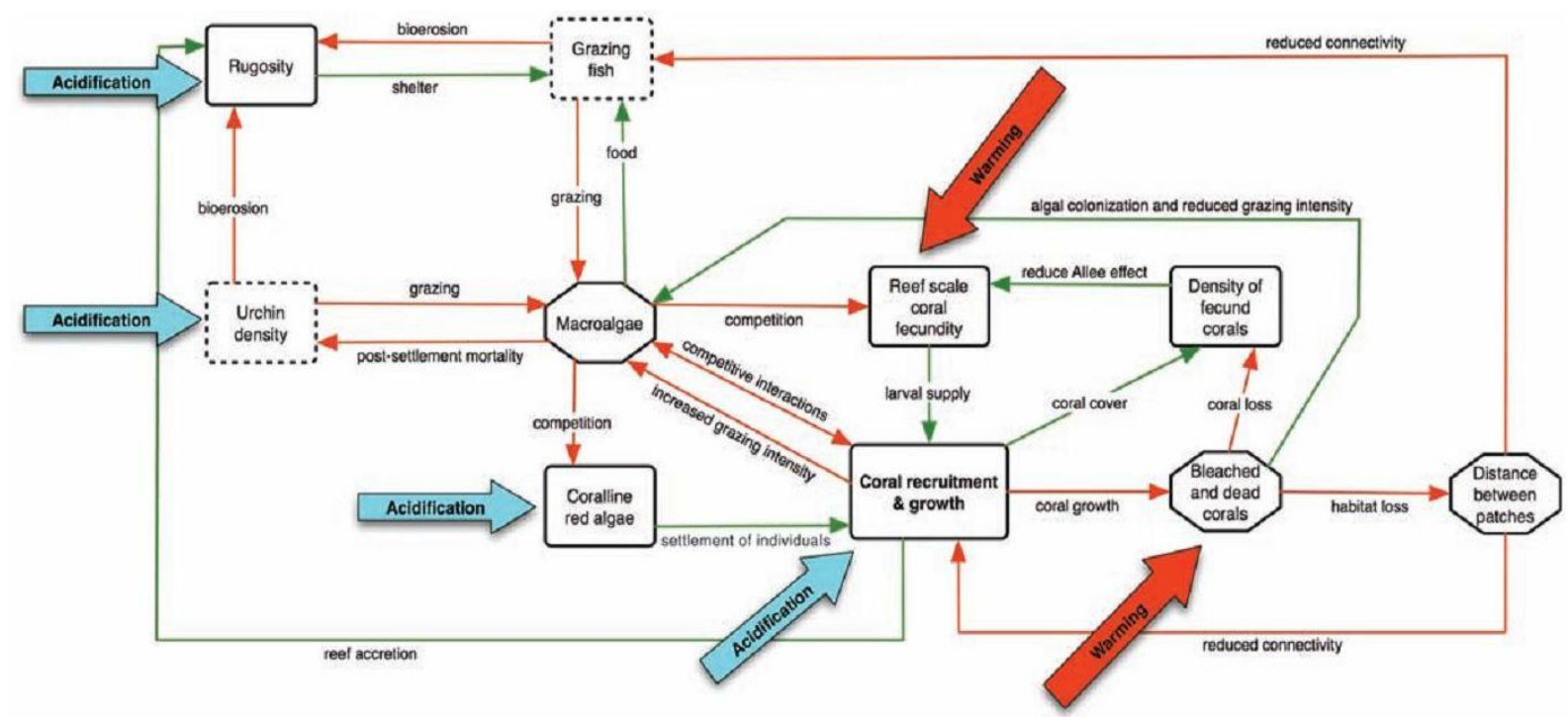

Figure 2. A simplified diagram of a coral reef ecosystem depicting critical functional groups and reef processes. These can be considered as key nodes where environmental stresses (warming, acidification) would exert effects that could cascade throughout the entire system because of feedback processes, both positive and negative (reproduced, with permission, from [7])

\subsection{Ecosystem structure}

Coral reefs and similar shallow-water habitats possess prominent structural features that can readily be captured and characterized using either in situ survey or remote sensing techniques. With respect to in situ surveys, various methods have been developed to estimate the topographic complexity or rugosity of the sea bottom [8]. This metric may be directly correlated with the species richness of the area, since a more complex three-dimensional structure would offer more potential niches than a relatively homogeneous one.

A number of methods are employed to estimate abundance and distribution of key species on a reef [4]. Understandably, it is impossible to count and identify all species, so the focus is on major groups that perform key functions. Examples of such "functional groups" include the hard corals themselves, coral-associated fish such as members of the family Chaetodontidae, coralline algae such as the genus Halimeda, grazing invertebrates such as the black-spined sea urchin Diadema, and the predatory starfish Acanthaster.

In the case of remote sensing, algorithms are continually being developed to resolve three-dimensional structure from images obtained either from low-flying aircraft or from satellites $[9,10]$. As explained above, the more complex bottom structures are expected to harbor higher species diversity, although the need to ground-truth this remains indispensable. Where remote sensing images indicate high topographic complexity, surveys should be conducted at those very same sites to determine the actual numbers of key species, their distribution and their abundance. Only after a sufficiently large data set has been collected can statistically meaningful relationships between topographic complexity (as detected using remote sensing) and species diversity be established.

\subsection{Ecosystem function}

For coral reefs and, indeed, most habitats on land and in the ocean, the key functional parameter that effectively encompasses the state of an ecosystem, and which can be captured using simple techniques, remains to be primary production [11]. In the ocean, the quantification of the amounts of the pigment chlorophyll $a$ along with other pigments, and their changes over time, has served as an effective proxy for primary productivity, in lieu of actual estimates of phytoplankton or plant biomass.

The whole field of ocean color, or the estimation of levels of chlorophyll and other pigments using remote sensing, has undergone significant advances in recent years [12]. However, the water quality above reefs cannot be assessed directly using remote sensing because of the relatively shallow depths. Reflectance from the sea floor complicates the calculation of factors that are responsible for ocean color, including chlorophyll, suspended particles and dissolved organic matter [9]. Further research in this field is needed.

Other parameters that have been the object of sensor development over the years, such as sea surface 
temperature, dissolved oxygen, salinity and carbon dioxide (various papers, this symposium) relate directly to various aspects of ecosystem function, particularly through their effects on a range of physiological processes at the organismal level. Temperature directly influences metabolic rate, thus exerting effects on biological parameters such as growth, mortality and reproduction. For example, during the 1997-98 worldwide coral bleaching event, there was an opportunity in the Philippines to systematically monitor the response of corals transplanted on different kinds of substrates to the steady increase in sea surface temperature [13]. Two different species of corals demonstrated varying responses, with one of them, Porites rus, showing significantly better recovery after the warming episode. Dead corals were progressively covered by various species of algae.

Another study in the same geographic location examined parameters such as photosynthesis and respiration of various coral reef components over a seasonal cycle [14]. These included a species of hard coral, and interstitial communities (plant and animal) inhabiting sand and rubble substrates. The environmental parameters that were determined to exert the most significant effects on energy flow in the shallow reef habitat investigated were light, temperature and salinity. Ultimately, levels of these factors acting together would determine whether or not a particular site would exhibit a positive net balance of energy production over consumption.

Marine organisms that normally live under full oceanic salinity would experience physiological stress when exposed to lower salinities, such as during periods of intense precipitation, or when exposed to terrestrial runoff. Many animals are sensitive to levels of dissolved oxygen, and will suffer stress or even mortality if values of oxygen fall below a certain critical threshold. Carbon dioxide is an essential raw ingredient for photosynthesis. Recently, increasing levels of this gas in the atmosphere are believed to correlate directly with its concentration in the ocean, effectively decreasing oceanic $\mathrm{pH}$ via its interaction with the carbonate system.

Another major physical force in coral reef ecosystems is water motion. This factor operates on different scales [15]. At the molecular level, the presence or absence of significant water movement will influence the diffusion of important gases (oxygen, carbon dioxide) and nutrients in and out of the coral tissue. The delivery of these substances will determine effective photosynthetic and respiration rates [16]. On a larger scale, on the order of meters to hundreds of meters, the degree of water turbulence influences the zonation along a reef [17], since different coral species have varying tolerance levels to this factor. Some species thrive in exposed environments, while others prefer more sheltered locations.

\section{THE PROPOSED INTERNATIONAL NETWORK OF CORAL REEF ECOSYSTEM OBSERVING SYSTEMS (I-CREOS)}

The proposed system, I-CREOS (International Network of Coral Reef Ecosystem Observing Systems), described in [4], employs a whole suite of techniques and instrumentation, as outlined in Tab. 1.

Visual surveys continue to be among the most reliable means of collecting relatively accurate data. The same sites could be visited over regular periods of time, so that potentially valuable time series may be constructed of changes in hard coral cover and associated species (both benthic and pelagic). This method, however, is clearly the most time-consuming and logistically challenging within the suite of techniques contained in the proposed observing system. It requires the investigator to physically be located on site and collect data in real time. Nevertheless, it has a relatively long tradition involving many developing countries where the greatest density of reef areas and highest levels of species diversity, are found. Relatively well-trained personnel employ standardized methods to compare trends in coral cover, species diversity and broad community patterns even among large geographic regions. Such intercomparisons have already been made over the past several decades. Perhaps the best example of such an integrated network of coral reef monitoring activities over relatively large spatial and temporal scales is the Global Coral Reef Monitoring Network (GCRMN, [3])

The other techniques described in [4] represent varying degrees of sophistication in terms of the technology employed (Tab. 1). With this come considerations of acquisition cost, maintenance expenditures and the like. The various methods range from the use of simple sensors to the utilization of fully automated instrument packages. A further feature particularly in the more "high-tech" examples is the ability to convey data in near real-time via user-interfaces. This is aided by the increasing exploitation of the range of possibilities offered by the internet, for example.

The sensors or fully-automated systems are deployed in strategic parts of the reef depending on the specific questions posed by the investigator. An example would be the characterization of open ocean water masses impinging on the reef matrix. Another example would be description of the hydrological regime within the reef itself. The results of such observations may be applied to address ecological questions such as the transport of larvae which is critical in the connectivity of benthic communities located at varying distances from each other. 


\begin{tabular}{|c|c|c|}
\hline PARAMETERS & METHODS & $\begin{array}{c}\text { BIOLOGICAL OR ECOLOGICAL } \\
\text { ATTRIBUTE TO WHICH DIRECTLY } \\
\text { LINKED }\end{array}$ \\
\hline $\begin{array}{l}\text { Air temperature } \\
\text { Barometric pressure } \\
\text { Wind velocity } \\
\text { Currents } \\
\text { Waves } \\
\text { Tides } \\
\text { Depth } \\
\text { Coastal inundation, erosion } \\
\text { Sound (NEW) }\end{array}$ & $\begin{array}{l}\text { Moored instrument arrays } \\
\text { Satellite remote sensing } \\
\text { Hydrodynamic modeling }\end{array}$ & Physical habitat characterization \\
\hline $\begin{array}{l}\text { Sea surface temperature (SST) } \\
\text { Salinity } \\
\text { Photosynthetically available radiation } \\
\quad \text { (PAR) } \\
\text { Ultraviolet-B radiation (UV-B) } \\
\text { Nutrients }\end{array}$ & $\begin{array}{l}\text { Moored instrument arrays } \\
\text { Spatial hydrographic and water quality } \\
\quad \text { surveys } \\
\text { Satellite remote sensing } \\
\text { Hydrodynamic and ecosystem } \\
\text { modelling }\end{array}$ & $\begin{array}{l}\text { Organismal physiology } \\
\text { Photosynthesis }\end{array}$ \\
\hline $\begin{array}{l}\text { Turbidity } \\
\text { Sediments } \\
\text { Ocean color (proxy for phytoplankton } \\
\text { biomass) }\end{array}$ & $\begin{array}{l}\text { Moored instrument arrays } \\
\text { Satellite remote sensing } \\
\text { Hydrodynamic and ecosystem } \\
\text { modelling }\end{array}$ & $\begin{array}{l}\text { Primary productivity } \\
\text { Physical habitat characterization }\end{array}$ \\
\hline Species distribution & $\begin{array}{l}\text { Visual surveys } \\
\text { Satellite remote sensing } \\
\text { Ecosystem modelling }\end{array}$ & Community structure \\
\hline
\end{tabular}

Table 1. The suite of variables and methods contained in the proposed International Network of Coral Reef Ecosystem Observing Systems (I-CREOS, [4])

Furthermore, the different types of instrument packages described in [4] are designed to measure a range of physical parameters that directly influence the biology and ecology of reef organisms (Tab. 1). Photosynthetically available radiation (PAR) is critical for photosynthesis, while ultraviolet-B radiation is known to exert harmful effects at the cellular level. Temperature and salinity affect physiological processes as discussed in a previous section. Levels of nutrients, turbidity and sediments can promote or interfere with primary production processes.

An important parallel development is the increasing ability to characterize, on significant spatial scales, the degree of biological diversity in reef habitats as embodied, for example, in the ambitious Census of Marine Life program [18]. Breakthrough technologies include DNA barcoding and microchips combined with standardized sampling methods, upward looking and horizontal waveguide sonar techniques that cover large areas, the use of animal-borne sensors to measure environmental parameters, all supported by a combination of acoustic and satellite tracking techniques. The massive records are contained in the Census's Ocean Biogeographic Information System (OBIS) which is directly accessible to a wide range of users. 
This proposed system covers representative regions in the Pacific, Indian Ocean and Caribbean. Some research and demonstration activities are already ongoing. For the U.S. Pacific islands, for example, the Coral Reef Conservation Program of the United States' National Oceanic and Atmospheric Administration (NOAA) has established the Coral Reef Ecosystem Integrated Observing System (CREIOS). Elements of this program include benthic habitat mapping and long-term ecological, oceanographic, and water quality monitoring. Spatial scales covered range from the island, archipelago to the ocean basin, and temporal scales from diurnal through to seasonal and interannual.

Australia operates the Great Barrier Reef Ocean Observing System (GBROOS) as part of a nationwide Integrated Marine Observing System. The main aim of this program is to link the large-scale oceanic phenomena with processes observed at the scale of the reef and within the reef. Another large program in the Pacific is the Moorea Coral Reef (MCR) Long-Term Ecological Research (LTER) site established and funded by the U.S. National Science Foundation. The core of this program is the collection of spatially-explicit time series measurements to capture decadal trends in biology and physical forcing of the reef ecosystem. In French Polynesia, annual and biennial reef surveys are conducted by scientists from CRIOBE (Centre de Recherches Insulaires et Observatoire de l'Environnement de Polynésie Française). To complement the survey data, continuous measurements of selected environmental parameters are made by sensors deployed in strategic areas.

The above programs are complemented by a grass-roots community effort called the Coral Reef Environmental Observatory Network (CREON). The latter involves scientists from several coral reef research sites. Its purpose is to share expertise on deployment of environmental sensors that can provide real-time data streaming on ecological processes at different scales.

Other geographic regions currently have relatively low capacity in terms of developing and implementing coordinated and integrated monitoring programs of the marine environment. The Indian Ocean serves as an example [4], although there are a number of efforts in that region in terms of physical oceanographic observations and coral reef monitoring.

\section{SCIENTIFIC ADVANCES AND GAPS IN KNOWLEDGE}

Recent combinations of field observations, laboratory experiments and mathematical modelling have made it possible to directly relate gradients in environmental factors such as light and water motion to the fundamental niche dimensions of organisms, in this case, the hard corals [19]. Thus, environmental data derived from various observation systems could be used directly to interpret distribution patterns of benthic species on the basis of their physiology. For example, sufficient knowledge now exists for a number of coral species and associated reef organisms in terms of their respective physiological tolerances to factors such as light, temperature, water movement and sedimentation. Light-tolerant coral species can be distinguished from shade-adapted ones on the basis of their growth forms, and are situated in different zones of a reef. Lighttolerant species inhabit shallower parts such as the reef flat, and shade-adapted forms dwell in the deeper reef slopes. Different species also inhabit distinct reef zones on the basis of their adaptation to water motion, with specific forms found in the more exposed regions that have greater water turbulence, and others confined to more sheltered locations.

The above information helps explain broad species distribution patterns on a reef that can be detected by remote sensing. Advances in remote sensing now enable the monitoring of physical environmental data such as temperature, winds, solar radiation and water quality [9]. These parameters relate directly to aspects of coral reef health. Since field surveys and laboratory experiments are relatively more costly and time consuming, remote sensing presents a more available and convenient platform with which to scale up observations, and obtain information over larger geographic areas.

An additional object of interest, not only to researchers but also to managers and policy-makers, would be the ability to predict, from remotely-sensed images, the potential of habitats to harbor high species diversity. Such information would contribute to protection as well as better-planned harvesting strategies for resources. Various satellites are now able to distinguish up to 6 subtidal habitat types, such as coral reef, seagrass, sand, hard substrate, etc. [9]. Forerunners of these are Landsat (TM or ETM+ (Thematic Mapper or Enhanced Thematic Mapper)), SPOT HRV (Système Pour l'Observation de la Terre Haute Résolution Visible) and ASTER (Advanced Spaceborne Thermal Emission and Reflection Radiometer), and the remotely-sensed data obtained are mainly applied to mapping reef communities. Related to this, other significant achievements of the science of remote sensing include the ability to classify habitats on a range of spatial scales (tens of meters to thousands of kilometers) with increasingly better accuracy and resolution [10]. One limitation that remains, however, is that the statistical significance of relationships between habitat attributes and ecological parameters such as biodiversity and fish production still depends on the scale of observation. In order to overcome this limitation, further research should be conducted on a promising suite of indicators 
that includes geomorphology, benthic assemblages, rugosity and depth.

The major gaps in knowledge as regards monitoring the response of coral reef ecosystems to human-induced or natural environmental change pertain, in my view, to uncertainties in responses at the organismal level. As examples, I cite issues of temperature and ocean acidification, or synergies between the two variables.

For coral reef communities, one of the most recent, well-documented responses is the phenomenon of coral bleaching [20 and 21]. This is a biological response that takes place at the level of the coral colony, or more specifically, at the cellular level, between the coral host and its symbiotic algae (dinoflagellates, also known as "zooxanthellae"). Temperatures that rise beyond a critical threshold disrupt molecular signaling between coral host and symbiont, eventually resulting in the expulsion of the zooxanthellae into the surrounding water [22]. This effect cascades linearly to the entire community, so that during a severe bleaching event, entire populations of corals turn white. Some of these are unable to recover when temperatures return to normal, so that widespread coral mortality follows. Dead coral skeletons are rapidly settled by opportunistic organisms such as macroalgae, leading to a change in the general profile and function of the community [21].

A combination of advances in remote sensing [9] has enabled fairly accurate monitoring of sea surface temperatures on fine temporal resolutions (down to days). A product called the "degree heating week" (Fig. 3) has been developed which depicts the cumulative amount of time within which water temperatures exceed a known threshold for coral bleaching in a particular geographic region. This would allow for prediction, within reasonable error, of when and where a local bleaching event may occur. Quite appropriately, technical advances in remote sensing also enable the detection of coral bleaching from satellites (Fig. 4) so that the spatial extent of such a phenomenon can be better delimited. Hopefully, this would allow for appropriate scientific and management action to be effected in a timely manner.

Increasing ocean acidification is believed to directly affect calcium carbonate deposition by calcifying species, ranging from foraminiferans, mollusks, echinoderms to the hard corals themselves [5]. Some recent experiments, however, have yielded counterintuitive results. For example, a species of brittlestar found in many seafloor communities, Amphiura filiformis, was found to cope with elevated carbon dioxide levels and increasing acidification by enhancing calcification and metabolic rates [24]. This came with a cost, however, in the form of decreased arm muscle mass. In another study, this time on shellfish, two different species of the same oyster genus, Crassostrea, exhibited differing responses to reduced $\mathrm{pH}$. One species experienced reduced growth and calcification, while the other showed no response. Interestingly, both species still demonstrated net calcification and growth even when aragonite was undersaturated [25]. A temperate keystone species, the starfish Pisaster ochraceus, increased its growth under higher carbon dioxide concentrations, as well as under a combination of elevated temperature and carbon dioxide [26].

For coral reefs, the emerging picture is complicated when considering synergistic effects between temperature and $\mathrm{pH}$. In an experiment that examined high water temperature as a co-variable along with increasing carbon dioxide, different effects were observed for two major reef components, the coralline algae and the hard corals [27]. The coralline algae appeared to be more vulnerable to the combined stresses, with high carbon dioxide leading to negative productivity and high rates of net dissolution. Among the hard corals, there were differences between the branching and the massive forms. The branching Acropora actually experienced an increase in net productivity under elevated water temperature in the low and intermediate acidification scenarios. Thus, prediction of the combined effects of environmental stresses on overall ecosystem function is not at all straightforward.

In order to predict the responses of coral reef ecosystems to a possible future regime of lowered oceanic $\mathrm{pH}$ and increased acidification, these habitats should be integrated into an observational network for ocean acidification [28]. Standard methods to measure calcification rates in hard corals and other calcifying reef-associated organisms have long been in existence. Baseline calcification rates should be measured in representative individuals in reefs spanning a geographic range that is projected to be vulnerable to future changes in ambient aragonite saturation state. Such measurements should be repeated at appropriate time intervals. One example of a tool that could be employed for this purpose are the Autonomous Reef Monitoring Structures (ARMS) which are systematic collecting devices developed by the Census of Marine Life Coral Reef Ecosystems project [4, 18 and 28]. 


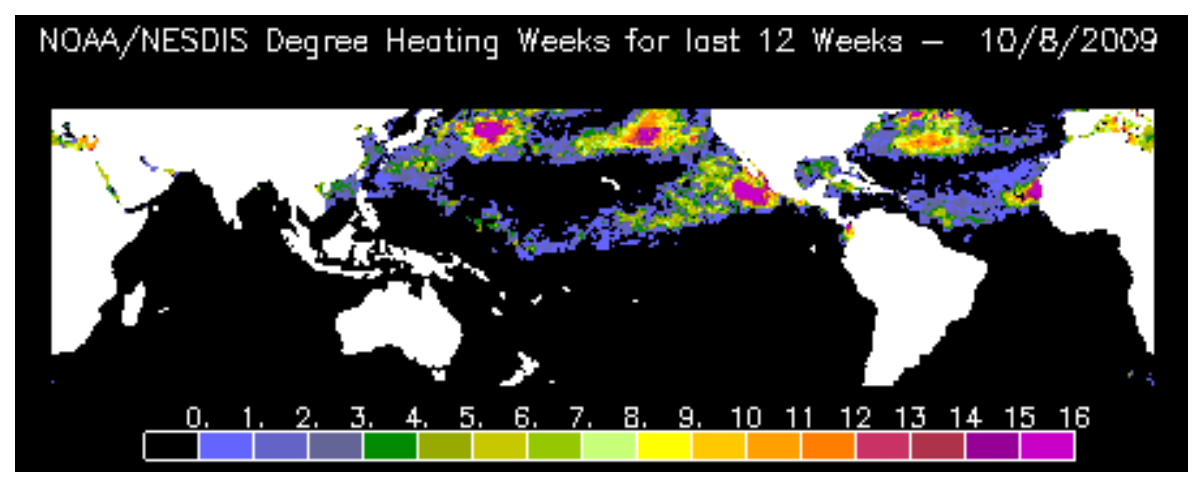

Figure 3. The degree heating week (DHW) product shows accumulated thermal stress, which can lead to coral bleaching. The scale goes from 0 to 16 degree-weeks. Spatial resolution is one-half degree (from NOAA National Environmental Satellite, Data and Information Service)
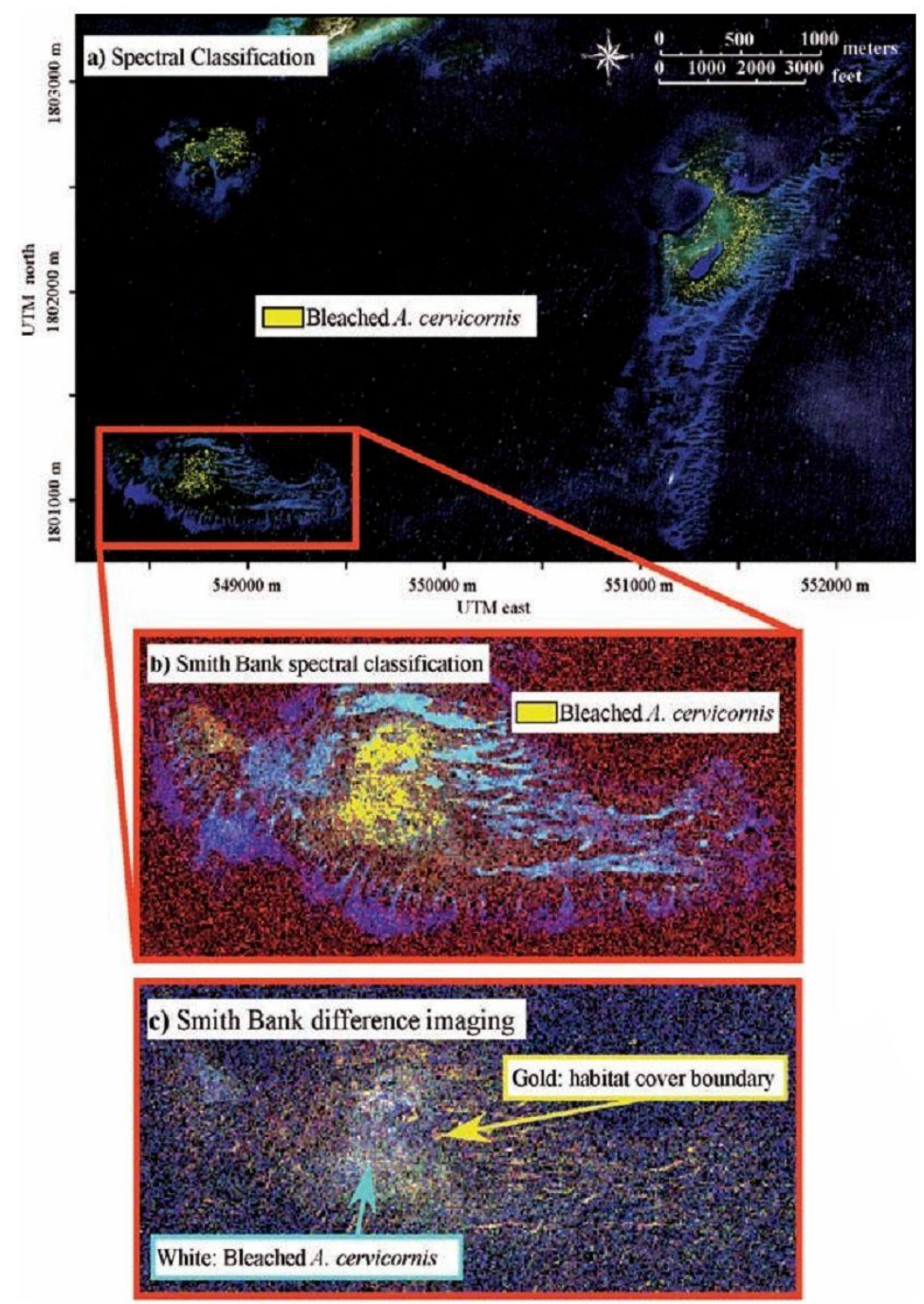

Figure 4. Satellite images showing bleached colony stands of the hard coral species Acropora cervicornis in a Caribbean site (reproduced with permission from [23]) 


\section{CURRENT NEEDS FOR A GLOBAL CORAL REEF OBSERVING SYSTEM}

Reference [4] provides a comprehensive overview of the state of the art in terms of designing and implementing an international observing system for coral reefs. The single greatest challenge is to engage as much of the broader scientific community as possible in a global effort. In particular, active participation from the developing world should be elicited, especially since this is where the vast majority of coral reefs, and the highest species diversity, are situated. It is also among developing countries, in contrast to developed ones, where there is greater dependence on coral reef resources for livelihood, and even for sustenance on a daily basis.

A regular monitoring programme targeted at the status of coral reef ecosystems, with an eye towards integrated management, would likely devolve in most countries to either academic institutions or government research agencies. In some instances, non-governmental organizations (NGO's) take up this task when resources and manpower are limited. In the so-called Third World, the various institutions and agencies remain at differing levels of capacity. The latter is reflected in terms of the number of qualified, in-house personnel, the kind of equipment available, the level of maintenance of such equipment, and resources allocated for day-to-day operations. Nevertheless, a growing number of countries to date harbor the requisite manpower, technical skills, infrastructure and equipment to carry out basic monitoring at some level. This is partly a result of the tireless efforts at capacity building over many decades by a number of international organizations and NGO's.

In order to actively incorporate developing country scientists into a global monitoring network, a logical take-off point is the Global Ocean Observing System (GOOS) which at the present time is hosted by the Intergovernmental Oceanographic Commission (IOC) of UNESCO (United Nations Educational Scientific and Cultural Organization). An advantage of Unesco-IOC is that it possesses an international mandate that allows it to engage government representatives up to the highest levels in various programs of action. There are clear procedures by which agreements could be reached and commitments made, including commitments of financial support and involvement of agencies and institutions at the national and local levels. As mentioned elsewhere in this paper, an active ongoing programme under the GOOS umbrella is the Global Coral Reef Monitoring Network (GCRMN). This existing initiative could dovetail with, for example, the proposed I-CREOS [4]. The extensive network of reef scientists who participate in the GCRMN through their on-site monitoring could, over time, incorporate the kinds of techniques and instrument platforms being advocated in I-CREOS.

Elements of the model program incorporated in ICREOS could be introduced in regions where such aspects are either weak or non-existing. Efforts would start with the fundamentals, such as baseline characterizations of the status of coral reef habitats. These would require only rudimentary knowledge and skills. However, a parallel focus should be on capacitybuilding, another strong feature in the mandate of Unesco-IOC. As more and more nations within a region are entrained into the system, the various aspects of the monitoring program could be scaled up in terms of coverage and sophistication, and monitoring at regular time intervals could be implemented.

Needless to say, some of the main issues would involve the cost of acquisition of new technology, and, on the long term, the cost of maintenance. Such considerations must always be included when recommending technical packages to developing country institutions. The latter must also already have the requisite qualified manpower to implement the kinds of monitoring requirements envisioned in I-CREOS. Or, at the least, provisions should be made for the necessary training of local personnel.

In order to implement this rather ambitious programme, financial assistance is required. With the current global economic climate, it would be challenging to source funds on a sustained basis to implement the various aspects of the programme, particularly in the developing countries. Effort would have to be exerted to convince national governments to commit to such a programme, highlighting the fact that it is they and their constituents who have the most stake in its successful implementation. Wherever possible, the private sector should be tapped for additional resources. Possible candidates would be the oil, gas and other energy industries.

\section{THE PANEL FOR INTEGRATED COASTAL OBSERVATIONS (PICO)}

The Panel for Integrated Coastal Observations (PICO) was created in 2008 as a subcommittee of the Scientific Steering Committee of GOOS. Its mandate is to formulate an action plan in order to guide the establishment of a global "system of systems" for observing coastal ecosystems and processes [29]. Its working platform is the document "An implementation strategy for the coastal module of the Global Observing System" [30] which is the product of numerous meetings and consultations by a wide range of coastal researchers and management practitioners over many years. 
For the initial phase of the action plan, attention will be given to developing indicators for a selected set of phenomena considered to be of relevance to the greatest number of geographic regions, viz.:

Impacts of sea level rise and coastal flooding events on marine ecosystems and coastal communities;

Changes in the risk of human exposure to waterborne pathogens;

Impacts of ocean acidification on the growth and abundance of calcareous organisms;

Impacts of modification and loss of critical habitats;

Time-space extent of hypoxic events and their impacts; and

Changes in the abundance of exploitable living marine resources.

The indicators will be used for timely assessments of these phenomena in order to guide appropriate management action. This initiative should be integrated with that of I-CREOS and the GCRMN since, at least in the case of coral reef ecosystems, common needs are being addressed. In many instances, the same networks of scientists and institutions will likely be tapped. Hence, incorporating all of these and other similar initiatives into a common framework based on a unified strategy will save time, resources and manpower, and realize the task at hand more effectively. Again, a wellplaced international organization such as Unesco-IOC can play a strategic role.

\section{CONCLUSIONS}

Much progress has been realized in developing a knowledge base on the basic structure and function of coral reef ecosystems. This is accompanied by a solid body of evidence on the effects of anthropogenic stresses on reefs such as overexploitation of resources, pollution, and physical habitat degradation. Newer concerns pertain to the more recently recognized adverse effects of the changing climate, as manifested in rising sea surface temperatures, acidification of the water, and changes in storm patterns. All of these developments lend urgency to the task of developing an integrated, global observing system for coral reefs. This task is by no means trivial. It requires significant commitment from national governments and the various local implementing agencies within countries, in terms of manpower, time, and financial resources. The single biggest challenge is how to engage the developing countries and the broad network of scientists they represent.

\section{REFERENCES}

1. Dubinsky, Z., ed. (1990). Coral Reefs: Ecosystems of the World Vol. 25, Elsevier Science, Amsterdam, pp 550.

2. Jones, G.P., Almany, G.R., Russ, G.R., Sale, P.F., Steneck, R.S., van Oppen, M.J.H. \& Willis, B.L. (2009). Larval Retention and Connectivity Among Populations of Corals and Reef Fishes: History, Advances and Challenges. Coral Reefs 28(2), 307-325.

3. Wilkinson, C. (2008). Status of Coral Reefs of the World: 2008, Global Coral Reef Monitoring Network and Reef and Rainforest Research Center, Townsville, Australia, pp 1-296.

4. Brainard, R. \& Co-Authors (2010). "An International Network of Coral Reef Ecosystem Observing Systems (I-CREOS)" in these proceedings (Vol. 2), doi:10.5270/OceanObs09.cwp.09.

5. Iglesias-Rodriguez, M. \& Co-Authors (2010). "Developing a Global Ocean Acidification Observation Network" in these proceedings (Vol. 1), doi:10.5270/OceanObs09.pp.24.

6. Manzello, D., Kleypas, J., Budd, D.A., Eakin, C.M., Glynn, P.W. \& Langdon, C. (2008). Poorly Cemented Coral Reefs of the Eastern Tropical Pacific: Possible Insights into Reef Development in a High- $\mathrm{CO}_{2}$ World. Proc. Natl. Acad. Sci. USA 105(30), 10450-10455.

7. Hoegh-Guldberg, O., Mumby, P.J., Hooten, A.J., Steneck, R.S., Greenfield, P., Gomez, E., Harvell, C.D., Sale, P.F., Edwards, A.J., Caldeira, K., Knowlton, N., Eakin, C.M., Iglesias-Prieto, R., Muthiga, N., Bradbury, R.H., Dubi, A. \& Hatziolos, M.E. (2007). Coral Reefs under Rapid Climate Change and Ocean Acidification. Science 318(5857), 1737-1742.

8. Wilson, S.K., Graham, N.A.J. \& Polunin, N.V.C. (2007). Appraisal of Visual Assessments of Habitat Complexity and Benthic Composition on Coral Reefs. Mar. Biol. 151(3), 1069-1076.

9. Mumby, P.J., Skirving, W., Strong, A.E., Hardy, J.T., LeDrew, E.F., Hochberg, E.J., Stumpf, R.P. \& David, L.T. (2004). Remote Sensing of Coral Reefs and their Physical Environment. Mar. Pollut. Bull. 48(3-4), 219228.

10. Mellin, C., Andréfouët, S., Kulbicki, M., Dalleau, M. \& Vigliola, L. (2009). Remote Sensing and Fish-Habitat Relationships in Coral Reef Ecosystems: Review and Pathways for Systematic Multi-scale Hierarchical Research. Mar. Pollut. Bull. 58(1), 11-19.

11. Platt, T., ed. (1981). Physiological Bases of Phytoplankton Ecology, Canadian Bulletin of Fisheries and Aquatic Sciences, Department of Fisheries and Oceans, Ottawa, Canada, 346 p.

12. Yoder, J. (2010). "Ocean Colour Radiometry: Early Successes and a Look Towards the Future" in these proceedings (Vol. 1), doi:10.5270/OceanObs09.pp.43.

13. Yap, H.T. (2004). Differential Survival of Coral Transplants on Various Substrates under Elevated Water Temperatures. Mar. Pollut. Bull. 49(4), 306-312. 
14. Yap, H.T., Montebon, A.R.F. \& Dizon, R.M. (1994). Energy Flow and Seasonality in a Tropical Coral Reef Flat. Mar. Ecol. Prog. Ser. 103, 35-43.

15. Madin, J.S., Black, K.P. \& Connolly, S.R. (2006). Scaling Water Motion on Coral Reefs: From Regional to Organismal Scales. Coral Reefs 26(4), 635-644.

16. Montebon, A.R.F. \& Yap, H.T. (1995). Metabolic Responses of the Scleractinian Coral Porites cylindrica Dana to Water Motion. I. Oxygen Flux Studies. J. Exp. Mar. Biol. Ecol. 186(1), 33-52.

17. Madin, J. S. \& Connolly, S. R. (2006). Ecological Consequences of Major Hydrodynamic Disturbances on Coral Reefs. Nature 444(7118), 477-480.

18. O'Dor, R. \& Co-Authors (2010). "Bringing Life to Ocean Observation" in these proceedings (Vol. 1), doi:10.5270/OceanObs09.pp.29.

19. Hoogenboom, M.O. \& Connolly, S.R. (2009). Defining Fundamental Niche Dimensions of Corals: Synergistic Effects of Colony Size, Light, and Flow. Ecology 90(3), 767-780.

20. Douglas, A.E. (2003). Coral Bleaching-How and Why? Mar. Pollut. Bull. 46(4), 385-392.

21. Baker, A.C., Glynn, P.W. \& Riegl, B. (2008). Climate Change and Coral Bleaching: An Ecological Assessment of Long-term Impacts, Recovery Trends and Future Outlook. Estuar. Coast. Shelf Sci. 80(4), 435-471.

22. Weis, V.M. \& Allemand, D. (2009). What Determines Coral Health? Science 324(5931), 1153-1155.

23. Rowlands, G.P., Purkis, S.J., \& Riegl, B.M. (2008). The 2005 Coral-bleaching Event Roatan (Honduras): Use of Pseudo-invariant Features (PIFS) in Satellite Assessments. J. Spatial Sci. 53(1), 99-112.

24. Wood, H.L., Spicer, J.I. \& Widdicombe, S. (2008). Ocean Acidification may Increase Calcification Rates, But at a Cost. Proc. Biol. Sci, 275(1644), 1767-1773.

25. Miller, A.W., Reynolds, A.C., Sobrino, C. \& Riedel, G.F. (2009). Shellfish Face Uncertain Future in High $\mathrm{CO}_{2}$ World: Influence of Acidification on Oyster Larvae Calcification and Growth in Estuaries. PLOS ONE 4(5), e5661.

26. Gooding, R.A., Harley, C.D.G. \& Tang, E. (2009). Elevated Water Temperature and Carbon Dioxide Concentration Increase the Growth of a Keystone Echinoderm. Proc. Natl. Acad. Sci. USA 106(23), 93169321.

27. Anthony, K.R.N., Kline, D.I., Diaz-Pulido, G., Dove, S. \& Hoegh-Guldberg, O. (2008). Ocean Acidification Causes Bleaching and Productivity Loss in Coral Reef Builders. Proc. Natl. Acad. Sci. USA 105(45), 17442-17446.

28. Feely, R. \& Co-Authors (2010). "An International Observational Network for Ocean Acidification" in these proceedings (Vol. 2), doi:10.5270/OceanObs09.cwp.29.

29. Malone, T. \& Co-Authors (2010). "Building a Global System of Systems for the Coastal Ocean: A Strategic Action Plan for Implementing the Coastal Module of
GOOS" in these proceedings (Vol. 2), doi:10.5270/OceanObs09.cwp.59.

30. An Implementation Strategy for the Coastal Module of the Global Ocean Observing System. (2005). GOOS Report No. 148. IOC Information Documents Series No. 1217, UNESCO. 